\title{
ZÉ, o homem político em cena
}

$Z E ́$, the politician on the scene

\author{
Edélcio Mostaço
}

Edélcio Mostaço

Doutor em Artes Cênicas pela Escola de Comunicações e Artes (ECA) da Universidade de São Paulo (USP). Professor titular do Departamento de Artes Cênicas do Centro de Artes (Ceart) da Universidade do Estado de Santa Catarina (Udesc).

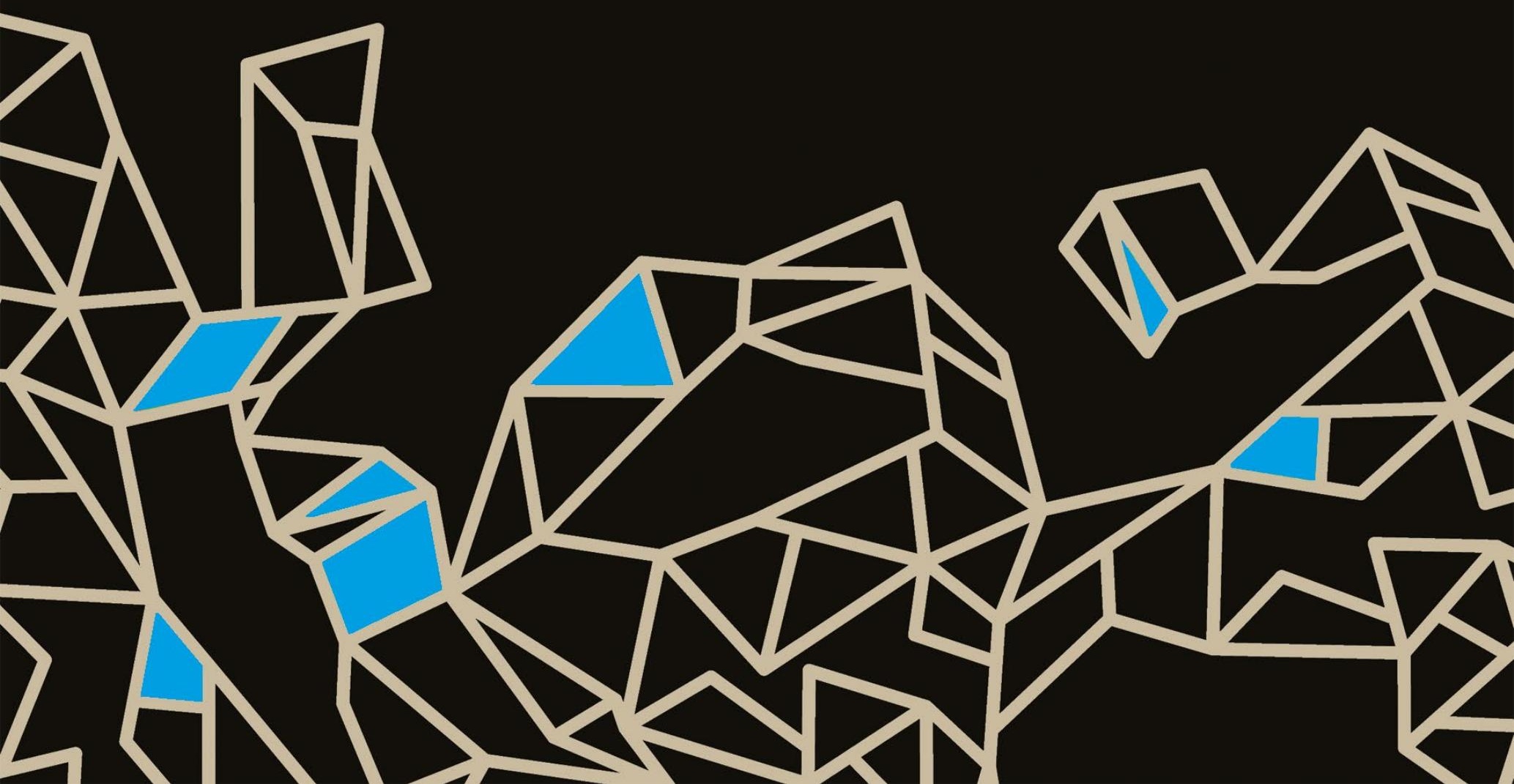




\section{Resumo}

O texto enfoca as dimensões políticas que perpassam a figura de Zé Celso Martinez Corrêa, encenador brasileiro e líder do Teatro Oficina. Desde suas origens marcadas pelo existencialismo até as condutas derivadas de sua concepção de tragicomediorgya, essa trajetória se mostra fortemente marcada pelas suas participações políticas e postura cidadã.

Palavras-chave: Zé Celso, Oficina, Tragicomediorgya.

\section{Abstract}

The text focuses on the political dimensions that permeate the figure of Zé Celso Martinez Corrêa, a Brazilian director and leader of Teatro Oficina. From its origins marked by existentialism to the behaviors based on his conception of tragicomediorgya, his trajectory is strongly marked by his political participation and his citizen posture.

Keywords: Zé Celso, Oficina, Tragicomediorgya.

\section{Berço}

"Na ordem natural, a cidade tem precedência sobre a família e sobre cada um de nós individualmente", declara Aristóteles em Política (1988, p. 16), ao balizar o que cada ser humano é em relação ao coletivo ao qual pertence. A trajetória de José Celso Martinez Corrêa - o Zé Celso do Teatro Oficina se encontra profundamente marcada, seja enquanto artista ou enquanto cidadão, por esse desígnio que implica em distinguir o útil do nocivo, a dor do prazer e o justo do injusto - como situa o dilema do ser político o filósofo grego em seu raciocínio.

Nascido em 1937 na cidade de Araraquara, no interior do estado de São Paulo, Zé Celso foi um menino tímido e doentio, e sua família alimentava expectativas de que ele se tornaria padre. Não foi o que aconteceu. Adolescente, ele frequentava a piscina do Clube Araraquarense, o mais distinto da urbe e, enredado por colegas, acabou integrando o Centro Cultural Alberto Torres, de indefectível perfil autoritário e reacionário, considerado uma das portas de entrada para os jovens rumo à Ação Integralista comandada por Plínio Salgado. 
O Estado Novo, naquele quadrante histórico, fazia acreditar que todo o mal estava na esquerda - motivo pelo qual um grupo de integrantes do Centro Cultural desbaratou um comício de comunistas no centro de Araraquara aos gritos de "abaixo os agentes de Moscou!" Zé Celso, porém, cresceu, abandonou aquelas ideias antidemocráticas da primeira adolescência e rumou, em 1955, para São Paulo, onde entrou no curso de direito da Universidade de São Paulo (USP), instalado no Largo de São Francisco. Nos corredores da vetusta instituição, tomou contato com as novíssimas ideias do Instituto Superior de Estudos Brasileiros (ISEB) sobre o Brasil e a filosofia de JeanPaul Sartre, resumida em uma publicação com o título de $O$ existencialismo é um humanismo (1973).

Uma frase abreviava todo o escrito: "a existência precede a essência" (SARTRE, 1973, p. 12). Além de ouvir bossa nova, frequentar barzinhos nos finais de tarde ou festinhas nas casas dos participantes, aquele pequeno grupo de moças e rapazes fazia cara de tédio para atender à solicitação existencial antes de alcançar a essencial; decidiram, portanto, iniciar um movimento de cultura no grêmio da faculdade, denominado "a Oficina" - uma espécie de fábrica para o novo homem que divisavam no futuro, amplamente amparado em experiências de vida que fornecessem lastro para a construção de suas essências. Entre outros, estavam no grupo Amir Haddad e Renato Borghi. Zé Celso se tomava, então, como autor, mostrando a todos uma peça que carregava debaixo do braço: Vento forte para papagaio subir, reminiscências de sua contraditória juventude no interior paulista, em um tempo e um espaço que agora desprezava e do qual queria definitivamente livrar-se - um largo passo de desapego relativo à sua adolescência medíocre, divisando agora os amplos céus que o aguardavam ao cortar o fio de papagaio que o prendia à terra, podendo finalmente rodopiar livre e deixar-se levar pelo vento existencialista.

A transformação do grupo noviço em profissional deu-se em 1958, após vencer um festival amador de teatro e ganhar a certeza de que o palco era seu destino. Essa opção se concretizou com a criação da empresa então formada por Renato Borghi, Ronaldo Daniel, Jairo Arco e Flexa, Moracy do Val, Paulo de Tarso e Zé Celso, que tomou o símbolo da bigorna como distintivo e o nome de Oficina como marca. Sem elenco e querendo estrear um novo texto nascido no Seminário de Dramaturgia, Augusto Boal convidou o Oficina 
para a montagem de Fogo frio, no Arena, do qual Zé Celso foi assistente de direção. A montagem não deu muito certo e atritos entre os dois grupos indicavam claramente os rumos políticos de um e de outro: o Arena era autoritário e seguia as diretrizes preconizadas pelo Partidão; o Oficina, por sua vez, guiava-se pelas ideias desenvolvimentistas do ISEB e anunciadas por Juscelino Kubistchek. Um era formado por militantes artísticos de uma causa, e o outro fazia da arte um laboratório para a realização pessoal. "Porque nós, do Oficina, éramos acusados de muito psicologismo, de emocionalismo, de rejeição pelos problemas políticos e sociais em troca da expressão exclusiva de nossas emoções pequeno burguesas", revelou Zé Celso (CORRÊA, 1998, p. 25) sobre os conflitos advindos daquela convivência. Foi então que Jean-Paul Sartre anunciou uma visita ao Brasil.

Cuba acabara de fazer uma revolução, tornando-se socialista; as eleições para um novo presidente que substituísse JK, no Brasil, estavam em curso, e Zé Celso e Boal adaptaram, às pressas, o roteiro cinematográfico $A$ engrenagem, da lavra do filósofo, para levarem à cena antes do pleito e homenagearem o ilustre visitante. "O que vocês vão fazer dessa engrenagem, o que vocês vão fazer do imperialismo", clamavam os atores de frente para o público, na militante encenação de Augusto Boal. Uma apresentação ao ar livre no Museu do Ipiranga foi proibida pela Censura e deslocada para o sindicado dos metalúrgicos, o que fez Zé Celso declarar: "aí entrava a noção sartriana de 'liberdade', de que não tem desculpa, de que tem que atirar nas coisas mesmo. Não tem pai, não tem mãe, não tem ditadura que lhe justifique, não tem opressão, não tem nada! Ou você age ou você se fode [...] Se você não acontece, não acontece nada" (CORRÊA, 1998, p. 27). O encenador já divisava, perfeitamente, a diferença entre o útil e o nocivo, entre o justo e o injusto'1.

\section{Acontecer e mais}

O confronto com o Arena, a censura, os ataques sofridos pela imprensa e pelos setores militantes e reacionários de plantão, fizeram o Oficina

1 O "político" é a percepção das sociedades humanas como fundamentadas sobre o conflito e os antagonismos que Ihe são intrínsecos; a "política" é o conjunto das práticas e instituições por meio das quais uma dada ordem é criada e organizada no contexto conflituoso produzido pelo político. Para desdobramentos, ver: MOUFFE, 2015. 
defrontar-se com vários obstáculos e tomar seu primeiro banho de realidade: as contradições sociais e os conflitos a que estavam expostos todos os que decidem optar por uma vita activa - conceito central da filosofia política de Hannah Arendt (2001) que se opõe à vida contemplativa, separando os que trilham os percursos do enfrentamento das forças sociais reativas à qualquer mudança, à moral dominante, aos tabus que a sociedade erige como escudo de proteção à sua integridade ética e institucional daqueles que, fieis a tais desígnios, sempre dizem amém.

Após Marx e Nietzsche, a vita activa tornou-se mais explicitamente política, implicando um posicionamento que ultrapassava o individual e o ético em busca também do coletivo e dos destinos em comum de toda uma sociedade. A palavra ação passou a designar o vínculo entre o ato praticado e a palavra que o situa. Encenado por Zé Celso em 1963, Pequenos burgueses aglutinou em um produto artístico todo seu projeto político-existencial até aquele momento, o cerne de sua ação:

a única verdade explícita conceitualmente através de Teteriev talvez seja 'a vida avança, velho, e quem não avança ao lado dela fica só, como você!', dita nas falas finais e que devem interpretar toda a peça e dar ao espectador o impacto da fatalidade, do fatum histórico que a própria personagem vai traçando muitas vezes sem saber. (CORRÊA, 1998, p. 54)

O golpe civil-militar de 1964 obrigou Zé Celso a procurar refúgio na Europa, onde permaneceu por um ano - em parte para repensar sua vida, em parte para conhecer teatros europeus, entre eles o Berliner Ensemble. Suas memórias, contudo, enfatizam duas coisas: um fenomenal porre de dois dias que tomou em Varsóvia e seu primeiro contato com a maconha, em Roma. Ao voltar, montou Os inimigos, novamente uma peça russa que refletia metaforicamente a situação brasileira e seu conflito de classes. A preconizada estratégia de aliança de classes efetuada pelo PCB desde 1958 dava sinais de desgaste e insustentabilidade diante dos avanços da ditadura - coisa que, aos poucos, foi fazendo ruir as expectativas de alguma reação à crítica situação do país. Para o Oficina e seu encenador, uma polêmica resposta àquele estado de coisas veio a seguir por meio da montagem de $O$ rei da vela, de Oswald de Andrade: um manifesto antropofágico, um visceral modo de 
responder à sociedade - a burguesia e seus aliados à esquerda - em que a vita activa demandava revisão e outros posicionamentos.

O período tropicalista, que costuma ser datado entre 1967 e 1968, foi um dos mais polêmicos no país. Se, por um lado, desmanchava-se o antigo pacto com a burguesia nacional preconizado pelo PCB (especialmente quando as elites percebiam que uma nova ordem econômica se desenhava no horizonte), de outro, agora militarizado pela ditadura e amplo respaldo dos EUA, os setores progressistas também não se mostravam coesos. Diversos rachas no setor indicam essa cisão, especialmente pela opção de vários grupos ao decidirem pela luta armada contra o regime. No plano social e cultural, essa mesma divisão podia ser percebida, isolando artistas fiéis aos desígnios do antigo CPC daqueles que deles manifestavam suas discórdias e propunham, como alternativa, outros modelos de intervenção. $O$ tropicalismo foi marcado por essa segunda opção.

Assim, O rei da vela foi pensado por Zé Celso como tendo

a necessidade de desmitificar, colocar esse público no seu estado original, cara a cara com sua miséria, a miséria do seu pequeno privilégio ganho às custas de tantas concessões, de tantos oportunismos, de tanta castração e recalque e de toda a miséria de um povo. O importante é colocar esse público em termos de nudez absoluta, sem defesas, incitá-lo à iniciativa, à criação de um caminho novo, fora de todos os oportunismos - batizados ou não de marxistas. [...] O teatro não pode ser um instrumento de educação popular, de transformação de mentalidades na base do bom-mocismo. A única possibilidade é exatamente pela deseducação, provocar o espectador, provocar sua inteligência recalcada, seu sentido de beleza atrofiado, seu sentido de ação protegido por mil e um esquemas teóricos e que somente levam à ineficácia. [...] A eficácia do teatro político hoje está no que Godard colocou a respeito do cinema: a abertura de uma série de vietnãs no campo da cultura - uma guerra contra a cultura oficial, a cultura de consumo fácil. Pois com o consumo não só se vende o produto, mas também se compra a consciência do consumidor. (CORRÊA, 1998, p. 96-98)

O teor político do discurso fala por si, bem como situa, sem ambiguidades, o agudo dissenso que o Brasil vivia naquele momento, como a percepção em relação à crescente indústria cultural que o tomava de assalto. 
Dentre todas as correntes artísticas que atravessaram nossos anos 1960, o tropicalismo foi a mais radical, unindo uma face estética e outra política ao propor ações públicas que desafiaram, com igual intensidade, as manifestações culturais, como até então conhecidas, e suas interfaces sociopolíticas ao apelar para ações inovadoras que almejavam se opor à Censura, à procura de experimentar novos formatos expressivos. Roda viva, a encenação de Zé Celso em 1968, pode ser tomada como uma suma tropical: valia-se do teor místico e ritual das celebrações católicas urdindo-as como uma missa negra, cuja fábula se centrava sobre a ascensão e queda de um cantor popular; a outra face, agora decalcada sobre as imagens da cultura de massa, do novo ídolo adorado por uma multidão de fiéis.

Ao final do mesmo ano, Caetano Veloso proferiu um violento discurso para a plateia e os telespectadores do festival da canção da rede Globo, ao ser vítima de longa e altissonante vaia promovida por alguns setores da plateia. Interrompendo É proibido proibir e iniciando seus vitupérios, Caetano urdiu um happening: uma inesperada intervenção que desmascarava as estruturas daqueles certames musicais regulados por interesses dos patrocinadores e do mercado, menos do que movidos por intenções artísticas. Milhões de brasileiros assistiram a performance, podendo constatar, sem veleidades, os limites e as tensões que a situação social e cultural havia adquirido.

As declarações de Zé Celso naquelas ocasiões, para além do discurso de Caetano, se evidenciam como atos políticos. Implicam, inicialmente, uma subjetivação, ou seja: uma desidentificação com uma dada comunidade à qual participavam, o que vem a ser outro modo de promover a desclassificação. No caso do teatro, em relação ao bom-mocismo promovido pelo teatro de resistência decorrente do CPC e seu público eufórico, também conhecido como "povo de pé"2; no caso da música, em relação à MPB, majoritariamente conduzida por artistas que também seguiam as diretrizes cepecistas e se alinhavam à chamada "esquerda festiva". $O$ tropicalismo atuou contra tais diretrizes sociopolíticas, tal público e todo o seu corolário de pressupostos advindos dos já esgotados pactos do início da década. Ao subjetivar-se,

2 A expressão "povo de pé" integrava uma das canções de Arena conta tiradentes, montagem efetuada pelo conjunto em 1967, que exaltava a resistência contra a ditadura, no formato do teatro coringa ali desenvolvido. 
o tropicalismo colocou-se enquanto sujeito político outro, outra voz presente na arena de poder em disputa. Essa heterologia continha seu desejo de ser outro, sua desclassificação enquanto suposto todo que a frente política apregoava. Esse novo lugar apontava para a insurgente luta armada, igualmente combatida pela mesma frente que se tomava como progressista. O político sempre incomoda, pois se recusa a participar das manobras promovidas pela política.

\section{Anos de repressão}

Decretado em 13 de dezembro de 1968, o Al-5 evidenciou-se a mais dura legislação criada pela ditadura civil-militar, abolindo o habeas corpus, fechando o Congresso nacional, instituindo a forte censura à circulação de informações e acobertando a tortura e os desaparecimentos de corpos daqueles que lutavam contra o regime, promovendo o fim da política no país.

A seguir, o Oficina conhece grande crise interna com a montagem de Na selva das cidades e convive alguns meses com o Living Theatre, convocado para partilhar experiências. A inciativa não deu certo e o conjunto paulista parte para uma grande viagem pelo Brasil apresentando antigos sucessos. Ao retornar, em 1973, monta a primeira criação coletiva profissional no país: Gracias, señor. Com a posterior saída de Renato Borghi, o Oficina original fica reduzido apenas à presença de Zé Celso, vivendo uma etapa difícil de sobrevivência. O espaço torna-se a Casa das Transas e shows de rock, pequenas montagens cênicas paralelas e o início das atividades ligadas ao vídeo e ao cinema arrebatam o encenador, até que sobrevém sua prisão, a tortura e o forçado exílio do país em 1974. Um longo documento por ele escrito, denominado S.O.S, não foi publicado em nenhum jornal, mas circulou em formato mimeografado entre muita gente. Nele, o apelo à ajuda se confundia com a análise política do país naquele momento.

Em Portugal, para onde se deslocou, o Oficina conhecerá novos ares. Em Lisboa, remonta Galileu galilei com fundas alterações no texto original, além de levar às ruas e praças o Ensaio geral do carnaval do povo. A montagem aproveitava motivos de Galileu e o formato das peças didáticas de Brecht. Cantando e sambando em praça pública, o elenco iniciava fazendo uma 
pirâmide humana assim constituída: embaixo do capital, o general; embaixo do general, o industrial; embaixo do industrial, o vigário; embaixo do vigário, o funcionário; embaixo do funcionário, o operário, embaixo do operário, o trabalhador agrário; embaixo do trabalhador agrário, as galinhas, os mendigos e o rebotalho; essa minha gente é a ordem ordinária; ordem constituída que a todo custo tem que ser mantida; amém.

A seguir, iniciava-se uma distribuição de pães, percorrendo os dois sentidos da pirâmide: aquele da "produção", de baixo para cima, e aquele da "distribuição", de cima para baixo, deixando evidente em que setores ocorria o acúmulo ou a escassez dos pães dentro do regime capitalista. O político tomou conta do grupo, em sua plena acepção, ao destacar a natureza fortemente conflitiva das sociedades humanas, de onde decorre a necessidade de interlocução entre a comunidade - a política em sua vigência - como modo de atuação.

Com Celso Lucas, Zé Celso dirigiu O parto para a televisão portuguesa, um documentário sobre a Revolução dos Cravos, o que estendeu seu alcance para milhares de espectadores. A seguir, rumou para Angola e depois Moçambique, onde filmou 25, sobre a libertação do país do jugo do colonialismo lusitano. Tais atividades vão se revelar, na sequência, fundamentais para Zé Celso reposicionar-se estética e politicamente: em Portugal, vivenciou uma revolução que baniu o fascismo do regime salazarista e instituiu uma das mais fortes democracias da Europa; nas ex-colônias conheceu a cultura africana e sua força, seus rituais, sua mística, seu profundo sentido gregário e comunitário.

Em 1979, após Lisboa e Paris, Zé Celso retorna ao Brasil ao lado de grande quantidade de ex-exilados e disposto a retomar seu antigo endereço teatral, que viveu, durante aqueles anos, como uma casa comercial de aluguel nas mãos de um empresário sem expressão. Reunindo novos integrantes, redimensionando por completo as atividades artísticas e investindo no emprego de novas mídias para se comunicar, nasce, em 1981, o Oficina Uzyna Uzona - um misto de usina cultural e zona de intercâmbios. A antiga arquitetura do teatro começou a ser desmontada, dando lugar a um imenso buraco que demandava outro projeto de construção. Enquanto esse não surgia, uma fase confusa e cheia de altos e baixos registra duas realizações 
que merecem destaque: a gravação de Caderneta de campo, um vídeo para a TV Cultura que foca na prática do te-ato iniciado em Gracias, señor, agora multiplicado em um sem-número de usos que permitiram a sobrevivência do grupo por meio de algumas verbas; e a montagem de $O$ homem e o cavalo, de Oswald de Andrade, em 1985, dentro de um ciclo de leituras de textos proibidos pela Censura e apresentado apenas um dia no Teatro Sérgio Cardoso, com um elenco estelar que reunia o grupo: Raul Cortez, Elke Maravilha, Dionísio Azevedo, Os Parlapatões e uma infinidade de outros artistas de várias linguagens.

Em 1993, com a estreia de Ham-let dentro no remodelado espaço concebido e realizado sob a supervisão de Lina Bo Bardi, uma rua cultural destinada a dar em um teatro-estádio no centro do quarteirão, Zé Celso e o Oficina Uzyna Uzona viveram intrépidos episódios de lutas - não apenas com os órgãos de tombamento do imóvel como, sobretudo, com o poder econômico do Grupo Empresarial Silvio Santos, vizinho do teatro e que ambicionava transformar todo aquele quadrilátero de terreno em um shopping center. Foram momentos em que o político cedeu à política, à arte da diplomacia e da negociação, indispensáveis para sobreviver aos tumultos e implantar o que era uma utopia: dotar o bairro do Bexiga de uma ativa vida cultural, resistindo à gentrificação.

No novo espaço de Lina e seguindo novas diretrizes estéticas advindas das diversificações expressivas e de atuação a que o grupo se lançara - criar o Teatro de Estádio, fundar a Universidade Popular e incentivar em definitivo o Projeto Bexigão -, Zé Celso forjou o conceito de tragicomediorgya dentro de um conjunto de parâmetros que vão orientar o coletivo até os dias atuais.

\section{O canto do bode}

Do ponto de vista político, Zé Celso abandonou certos radicalismos que o marcaram em anos anteriores e passou a acreditar no poder do próprio teatro:

de certa maneira, a situação que a gente vive aqui não é muito diferente da de Canudos. A solução que tem de ser encontrada é política, porque o teatro é um lugar que propõe o mundo à política, quer dizer, o teatro é o lugar onde se busca o reforço do poder humano na intervenção dos 
acontecimentos, da máquina social. Então nós, como artistas, temos de encontrar uma solução não violenta, uma situação de não-guerra, nós temos que vencer pelo teatro. (LOPES; COHN, 2008, p. 224)

Tal solução foi conceitualmente sustentada pelo revigoramento da tragédia, pelo grotesco inerente à comédia e um forte apelo à condição orgiástica que deve presidir todas as escolhas e decisões, colorindo com outros tons a vida comunitária.

A tragicomediorgya foi empregada pela primeira vez no espetáculo Bacantes (1995) como um amálgama de princípios e noções processuais devidamente maceradas e deglutidas sob influxo da antropofagia, emanada do Manifesto antropófago de 1928. Ela intenta entrelaçar em viés aprofundado a arte e a vida, e suas origens mais remotas podem ser escavadas junto ao pensamento de Nietzsche - não apenas a noção de dionisismo (A origem da tragédia) mas, sobretudo, a de corpo como pensador (Humano, demasiado humano). Nessa acepção, pode-se falar em uma antropologia reversa, como articulada por Roy Wagner (2012), uma vez que a tragicomediorgya remonta ao ditirambo, às formas pré-cênicas do teatro ocidental em suas manifestações corais, míticas e coletivas. Porém, mais que simples soma ou subtração de noções anteriores, o que temos é a negação da logocêntrica cena ficcional a seguir fixada, bem como daquela dramática dialética, de cunho hegeliano, através de uma reversão de padrões estéticos e gêneros expressivos - uma territorialização em busca de novos agenciamentos. Essa arquitetônica ditirâmbica é supervisionada pelo impulso coral, arcaico e anterior à especialização dos formatos monológicos trágicos e cômicos, momento liminar marcado pela indistinção entre as fronteiras sacras e profanas.

Fundamente dialógica enquanto manifestação coletiva, a tragicomediorgya é também rizomática enquanto ser manifesto: desenvolve-se preferentemente por meio de prolongamentos e derivações do que de aprofundamentos no terreno temático escolhido, tecendo redes associativas ao invés de buscar a verticalidade das raízes. Privilegia, assim, mais a expressividade alegórica que a nucleação simbólica, embora ambos os procedimentos nela sejam discerníveis dado o agudo perspectivismo que a preside. 
O pulso orgíaco que Ihe dá o tônus energético enquanto predicado ritual indica uma desespecialização de funções sensuais, como se um fio mítico e onírico enovelasse o corpo dos atuadores e da plateia, cujo trânsito pelo erotismo é um convite à partilha de tempos e espaços. A carnavalização, na acepção dialógica de Bakhtin - paródia, inversão de valores, destronização de heróis, grotesco, orgia sacra, comutação de papéis, baixo corporal, entre outros - encontra aqui todos os seus componentes e procedimentos poéticos plenamente ativados.

A dimensão da crueldade artaudiana, também, sulca seus propósitos não apenas através dos expedientes previstos nos manifestos, mas também em outra direção: sua negação da metafísica e insistência no poder da peste enquanto desorganização e contágio, força dirigida aos nervos capaz de retirar as coisas de seu lugar. Outra componente aqui presente é a peça didática brechtiana, embora por meio de uma releitura que reorientou seus intentos iniciais para destacar, sobretudo, sua condição produtiva quanto à participação dos espectadores e seu convite a um perspectivismo diante dos conflitos e situações encenados. Temos, portanto, mais uma dobra, como pensada por Deleuze e Guattari (2007. p. 27), em que "um organismo é chamado a desdobrar suas próprias partes, sua alma animal ou sensitiva e abre-se a todo um teatro, teatro em que ela percebe e sente de acordo com sua unidade, independentemente do seu organismo e, todavia, inseparável dele", fomentando novos - quase sempre surpreendentes - vínculos de performatividade.

Nessa ontologia de transmutação, nessa máquina de guerra nômade, foram encenados cinco espetáculos tendo como tema Os sertões, baseados em Euclides da Cunha, apresentados entre 2000 e 2007. Ao radicar essa epopeia cênica nascida nos primórdios de nossa República e em estreita conjunção com nossa própria história, o Oficina afirmou e redefiniu sua própria concepção de anarquia, decorrente da constatação de que a an-archia primitiva implicava em uma democracia radical, horizontalizada quanto à sua comunidade de base e construída com as próprias mãos, enquanto trabalho que não mais distingue sua dimensão artística daquela cidadã. O Oficina voltou a ser uma oficina - espaço arquetípico onde se forja o futuro -, um futuro politicamente reorientado à produção de uma nova comunidade. 


\section{Referências bibliográficas}

ARENDT, H. A condição humana. Trad. Roberto Raposo. Rio de Janeiro: Forense, 2001.

ARISTÓTELES. Política. Trad. Mário da Gama Cury. Brasília: Editora UnB, 1988.

CORRÊA, J. C. M.; STAAL, A. H. C (org.). Primeiro ato: cadernos, depoimentos, entrevistas (1958-1974). São Paulo: Editora 34, 1998.

DELEUZE, G.; GUATTARI, F. Mil platôs: capitalismo e esquizofrenia. Trad. Peter Pal Pélbart e Janice Caiafa. São Paulo: Editora 34, 2007. v. 5.

LOPES, K. COHN, S. (org.). Encontros: Zé Celso Martinez Corrêa. Rio de Janeiro: Azougue, 2008.

MOUFFE, C. Sobre o político. Trad. Fernando Santos. São Paulo: Martins Fontes, 2015.

SARTRE, J. P. O existencialismo é um humanismo. São Paulo: Abril Cultural, 1973. (Coleção Os Pensadores).

WAGNER, R. A invenção da cultura. Trad. Marcela Coelho de Souza. São Paulo: Cosac Naify, 2012.

Autor convidado 
